\title{
Methods of determination of forces in the "wheel-rail" system
}

\author{
Tatyana Sych $^{1, *}$, and Andrey Kolomeets ${ }^{1}$ \\ ${ }^{1}$ Siberian Transport University, 630049 Novosibirsk, Russia
}

\begin{abstract}
Increase in the volume of heavy traffic on railways updates the requirements for ensuring transportation safety in conditions of continuous increasing in axle loads on the track. The purpose of the study is to review methods for determining the dynamic forces arising from interaction between the wheel and the rail during rolling stock movement. The numerical method is used to determine the values of relative strain of the rail web at the transducers locations. Model verification and estimation of the calculation accuracy for several methods of determining forces in the "wheel-rail" system has been performed. Methods for determining the loads arising in the wheel and rail system, as well as the results of calculating the three load components were obtained. Simulation tests of the proposed forces control method have been performed.
\end{abstract}

\section{Introduction}

In conditions of growing freight turnover, the task of reliable monitoring of dynamic forces affecting the track and caused by rolling stock on the network of railways is becoming increasingly important [1]. This problem is especially relevant in connection with increase in axle loads and introduction of heavy rolling stock around the globe [2-4]. Safety of traffic of freight and passenger rolling stock is directly related to timely identification of operational defects in the parts of rolling stock and track. Dynamic forces trigger development of fatigue cracks and are the cause of derailments, accidents and destructions [5].

Excessive dynamic forces cause progression of rail defects and development of fatigue cracks in the unsprung part of the carriage. Standard [6] with the norms of permissible effect on the track and test methods was introduced in the Russian Federation. There are various ways to determine these forces, but the number of studies on assessing the methods reliability is insufficient. It raises the need for research on the metrological support of methods for determining forces in the "wheel-rail" system.

Systems of continuous monitoring of wheel-rail interaction parameters have become widespread recently. These systems may use optical or laser sensors to determine the geometry of parts, maximum deflections, and strain sensors. In all cases, indirect information about the process is recorded, on the basis of which the decision is made on

* Corresponding author: tatyna979@mail.ru 
(non)admissibility of dynamic loads acting on the part. In accordance with [6], the methods for determining lateral and vertical forces transmitted from the wheel to the rail are strain gages on the rails, and strain gages on wheels with the frequency of recording of $250 \mathrm{~Hz}$. It is proposed to use the Schlumpf method [7] to determine lateral forces. A lot of methods for recording information have been developed, but metrological support of the methods is necessary for their wide application, reliability and accuracy of calculations.

Thus, the main purpose of the study is to analyze the stress-strain state of the rail when the wheel of the rolling stock is acting on it and metrological support of the methods of registering forces in the "wheel-rail" system. Reliable definition of lateral and vertical forces will help improve traffic safety, increase the service life of rails and carriage parts.

\section{Research methods}

The most common and investigated are the following two methods of placing sensors on the rail web to record the train load. The first method considered is the Schlumpf method, which is set forth in [6]. It uses a tensometric circuit assembled on the rail web, by which lateral forces are measured by the difference in the opposite bending moments occurring in the rail web under the action of lateral forces. Several measuring cross-sections of the rail can be used, in each four strain gages are installed (Fig. 1). The strain gages are placed on the rail web in pairs from external and internal side, one pair located at point $z_{1}$ and $z_{2}$ is higher than the neutral axis of the rail cross-section, the second pair located at point $z_{3}$ and $z_{4}$ is lower than that level.

The second method suggests using two measuring transducers in each section of the rail in the middle of the web near the $y-y^{\prime}$ neutral axis (Fig. 1). The transducers are oriented vertically [8], half-sum and half-difference of deformations are used for calculations, the data is recorded in several measuring cross-sections. There are alternative methods as well [9]. Computer and numerical methods can be used to perform detailed analysis of the state of the wheel and rail during their interaction for various arrangements of the primary transducers [10-13].

This study uses the finite-element rail model (type P65) with the cross-section in accordance with GOST R 51685 created for calculation, the model length was $6 \mathrm{~m}$. The simulation was performed in the SolidWorks software environment. An elastic base simulating the supports (Fig. 2, pos. 2) through equal intervals $\mathrm{L}$ was set according to the length of the rail (Fig. 2, pos. 1). The vertical component of elastic base $E$ comprised $10^{9}$ to $10^{12}(\mathrm{~N} / \mathrm{m}) / \mathrm{m}^{2}$.

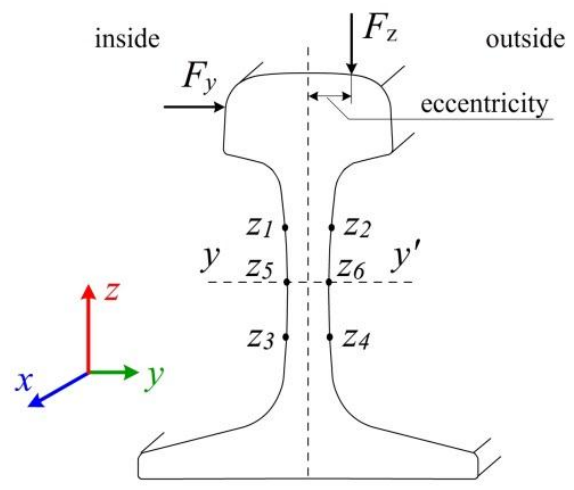

Fig. 1. Layout for determining the effect of force factors on the rail from the train load. $F_{z}$ is vertical force, $F_{y}$ is lateral force, $e$ is displacement in the cross-section (eccentricity). 
The strained state of the rail was studied with vertical force $F_{z}=100 \mathrm{kN}$ and zero eccentricity $e=0 \mathrm{~mm}$, the measuring cross-section for $L / 2$. These results will be used hereafter for comparison with other calculation options. The maximum local deflection in the force application area was 110 million $^{-1}$. Calculations for the model were compared for different boundary conditions. The discrepancy between the calculation results for fixing the face with rigid embedding and hard edge sealing calculated using the relative error formula (1) was $0.05 \%$. In (1): $\mathrm{s}\left(y-y_{l}\right), \mathrm{s}(y)$ are root-mean-square deviations of calculation results with two different parameter values $y$ or $y_{1}$, million $^{-1}$. The error in the calculation between the results obtained with a rigid edge seal and the roller was $0.4 \%$. With that, the effect of the fixing variant has a local nature at the model edges.

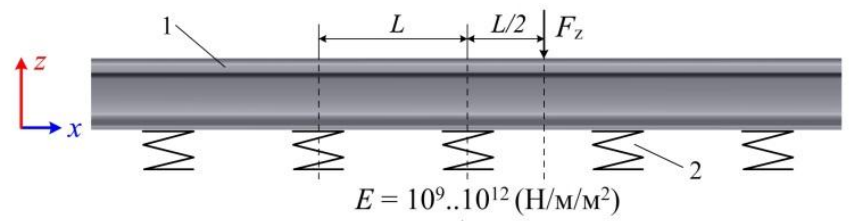

a)
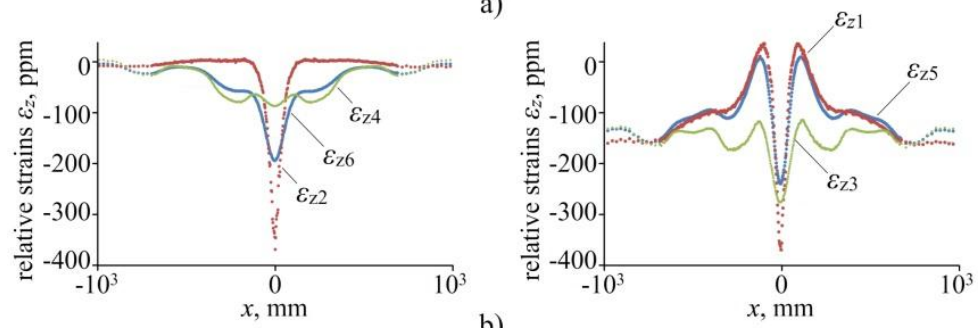

b)

Fig. 2. Mathematical rail model: $\mathrm{a}$ is the finite element rail model; $\mathrm{b}$ are the results of calculating the relative strain of the rail web near the neutral axis for $F_{z}=100 \mathrm{kN}$, $F_{y}=0, e=10 \mathrm{~mm}, E=10^{9} \mathrm{~N} / \mathrm{m} / \mathrm{m}^{2}$.

$$
\delta=\frac{s\left(y-y_{1}\right)}{s(y)} \cdot 100 \%
$$

With a decrease in the minimum dimensions of the finite elements from $5 \mathrm{~mm}$ to 2.5 $\mathrm{mm}$, the discrepancy in the calculation results was $0.82 \%$. The type of the load applied was varied to verify the model: when the point force was varied into force distributed along the edge, the discrepancy between results was $0.14 \%$. In case of replacement of the point force with the force distributed in an area, the discrepancy between results was increased to $1.7 \%$.

In operation, the force is irregularly acting on the wheel due to wobble, rolling of the wheel onto the ridge, and its squeezing. Elimination of the effect of this displacement on the calculation results will be important, since eccentricity causes occurrence of bending moment. Large values of the bending moment, in turn, cause additional errors in calculation of forces. In the second experiment, the point force in the model was displaced from the central point along the $\mathrm{y}$ axis by the value of $e=10 \mathrm{~mm}$. Figure 2, b demonstrates distribution of relative strains $\varepsilon_{z 1}, \varepsilon_{z 2}, \varepsilon_{z 3}, \varepsilon_{z 4}, \varepsilon_{z 5}, \varepsilon_{z 6}$ along the edges on both sides of the rail in accordance with numbering (Fig. 1). The half-sum of the relative strains in each rail web node (symmetrical strains) is calculated from the external and internal sides of the rail, their value is compared with the calculated results for each node in the first experiment with $e=0$. For comparison of two dependencies (the first one being the dependency of distribution $\varepsilon_{z} 6$ along the rail length at $F_{z}=100 \mathrm{kN}, e=0 \mathrm{~mm}$, the second one was obtained by calculation of symmetrical strains $\varepsilon_{z 5}$ and $\varepsilon_{z 6}$ ), discrepancy between them was found equal to $0.96 \%$ (1). In 
the course of the study, the results of the lateral load application were analyzed, separately and in combination with vertical force. When applying the lateral force equal to $F_{y}=25 \mathrm{kN}$, $F_{z}=0, e=0$, where $F_{y}=1 / 4 F_{z}$, as compared to the first experiment, relative strains of the rail web $\varepsilon_{z 6}$ reach the maximum of 75 million $^{-1}$, the model elasticity is associated with less flexural rigidity in the lateral force direction.

\section{Results}

After verification of the model, two ways of registering the rail strains were compared, which were discussed in the first section, and an estimate of the accuracy of forces calculation was made. The "RZD-2016" method [2] based on the principle of independence of the forces and the registration of data by strain gauge $z_{1} \ldots z_{4}$, like in [6], is widespread in the Russian railways. Forces are calculated with effect matrices that connect the forces acting on the rail to the stresses in the places where strain gages are fixed:

$$
\varepsilon_{i}=g_{i, j} \cdot f_{j}
$$

where $\varepsilon$ are relative strains, $\mathrm{g}$ is the obtained matrix of coefficients, $f$ are the loads applicable in the system, $i, j$ are matrix coefficients. The $g_{i, j}$ coefficient matrix is obtained in the course of calibration of the system with a specific combination of forces, which takes into consideration vertical component, lateral force, and bending moment.

$$
V=\left[\begin{array}{llll}
V^{0} & V^{1} & V^{2} & V^{3}
\end{array}\right]
$$

where $V^{0} \ldots V^{3}$ are columns of values of relative strains of tension sensors from one to four for various load types. To study the accuracy of this method, the calculated values of strains at different eccentricity of vertical force $e$ from 10 to $24.5 \mathrm{~mm}$. Dependency of relative strains $\varepsilon_{z}$ on $e$ has been built. It has linear nature for each of the four tension sensors (Fig. 3). The calculated vertical error of determination of vertical force $F_{z}$ comprised from 1.1 to $6.7 \%$ for $e=10 \mathrm{~mm}$ and $e=24.5 \mathrm{~mm}$, respectively, which confirms the impermissible increasing of error with increasing of eccentricity for this method. The assumption was verified suggesting that the error can be caused by the asymmetry of forces in the third and fourth gage experiments, when independent columns with positive and negative value e are obtained in matrix V. For each of the curves $R 1 \ldots R 4$ coefficients were calculated in the equation of function $k_{i, 1 . .4}$. These results allow simulating the systems with deliberately set displacement $d$. The columns of the effect matrices (3) were recalculated, and the calculated maximum error for artificial simulation of the eccentricity asymmetry was not more than $1.159 \%$ for $d=2 \mathrm{~mm}$. The sensitivity was compensated for each channel with the help of coefficients to reduce the error. When multiplying $\mathrm{V}_{3}$ in (3) by coefficient $k_{3}$ equal to 0.9773295 , the error in determination of $F_{z}$ is reduced to $\left(-6.624 \cdot 10^{-6} \%\right)$ with compensation for $\mathrm{V}_{2}$ in (3) with $k_{2},=0.977645$, the error is equal to $\left(-6.81 \cdot 10^{-6} \%\right)$. For this method, any deviation of the system from the conditions during calibration causes an unacceptable increase in errors. 


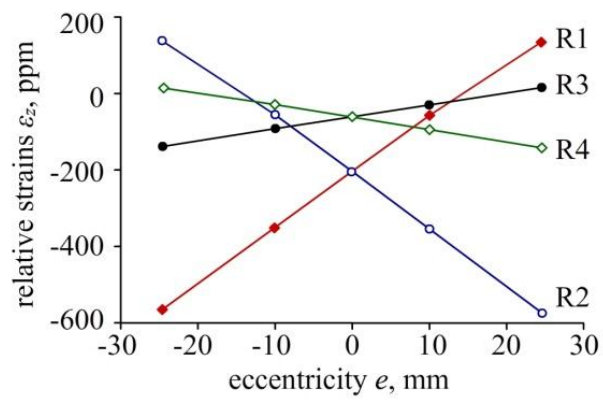

Fig. 3. Dependency of relative strains at the strain gages installation locations on value $e$.

The study of the effect of the sub-rail base rigidity $E$ on the calculation accuracy became the second important section of the work. Rigidity $E$ affects redistribution of rail strains, and, accordingly, the accuracy of forces determination [14]. Figure 4 represents distribution of strains $\varepsilon_{z}$ along the edges on the height of the rail web on two sides of the rail at $F_{z}=100 \mathrm{kN}, e=10 \mathrm{~mm}, E=10^{9}(\mathrm{~N} / \mathrm{m}) / \mathrm{m}^{2}$. Local reduction in compressive strains (Fig. 4, b) is caused by change in the rail web in this section. Figure 5 shows the results obtained for simulation rail load $\left(F_{z}=100 \mathrm{kN}, F_{y}=0, e=0\right)$ and $\mathrm{E}$ variations from $10^{8}$ to $10^{12}(\mathrm{~N} / \mathrm{m}) / \mathrm{m}^{2}$. With a change in rigidity, relative strain curves $\varepsilon_{z}$ have non-linear distribution along web height $\mathrm{z}$, where $z \in(44.5 \ldots 129.9) \mathrm{mm}$. Let us consider the site close to the neutral axis, where the web thickness is equal to $9 \mathrm{~mm}$ and the curves are linear with the accuracy of $0.95 \%$ (Fig. 5, b). It can be seen from the Figure that with variation in the rigidity of the under-rail base by five orders of magnitude, the neutral axis changes its height within the following limits: for variation of rigidity from $10^{8}$ to $10^{9}(\mathrm{~N} / \mathrm{m}) / \mathrm{m}^{2}$, neutral axis has the coordinate of $z=81.523 \mathrm{~mm}$. At this point, relative strains $\varepsilon_{z}$ do not change values $(-109$ million $^{-1}$ ), for $E \in 10^{9} \ldots 10^{10}(\mathrm{~N} / \mathrm{m}) / \mathrm{m}^{2}$, the neutral axis coordinate is increased to $z=84.492 \mathrm{~mm}$, at $\varepsilon_{z}=-113$ million $^{-1}$ within the specified rigidity change limits. With further increase of E, the neutral axis coordinate will be increased up to the value $z=91.465 \mathrm{~mm}$, the strains will comprise $\varepsilon_{z}=125$ million $^{-1}$. Even if the load is symmetrically applied in the cross section, if the rigidity $\mathrm{E}$ is varied within two orders of magnitude, the neutral axis can significantly change its coordinate between 3 and $7 \mathrm{~mm}$. When studying models with lateral forces, the distributions shown in Figure 5 change the character, the neutral axis rotates in the plane of the rail section. The value of displacement of the neutral axis characterizes the accuracy rate when installing strain gages. The errors resulting from displacement of the installation points of strain gages are calculated, and the norms for their installation are provided in [15].
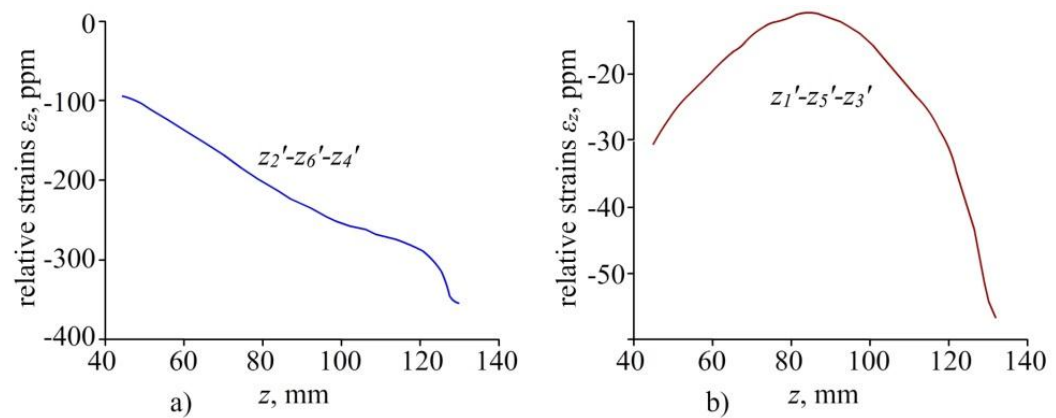

Fig. 4. Distribution of relative strains $\varepsilon_{z}$ by the rail web height from two sides; a - along the edge $z_{2}$ '$z 6^{\prime}-z 4_{6}^{\prime}{ }_{6}^{\prime}-z 4_{4}^{\prime}{ }^{\prime} ; \mathrm{b}$-along the edge $z_{1}{ }^{\prime}-z_{5}{ }^{\prime}-z_{3}{ }^{\prime}$. 


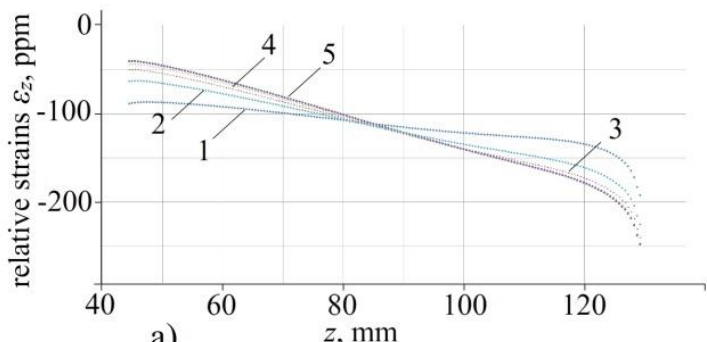

a)

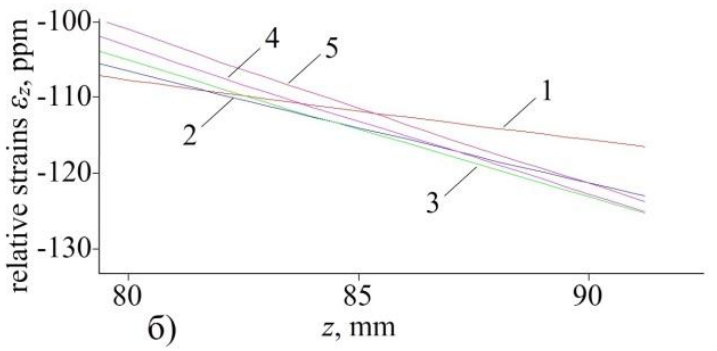

Fig. 5. Distribution of relative strains $\varepsilon_{z}$ by the rail web height from the external side: a - along the entire rail web height; $\mathrm{b}-$ at the linear section, $\boldsymbol{l}$ - at $\mathrm{E}=10^{8}(\mathrm{H} / \mathrm{M}) / \mathrm{M}^{2}, 2-\mathrm{E}=10^{9}(\mathrm{~N} / \mathrm{m}) / \mathrm{m}^{2}, 3-E=10^{10}$ $(\mathrm{N} / \mathrm{m}) / \mathrm{m}^{2}, 4-\mathrm{E}=10^{11}(\mathrm{~N} / \mathrm{m}) / \mathrm{m}^{2}, 5-\mathrm{E}=10^{12}(\mathrm{~N} / \mathrm{m}) / \mathrm{m}^{2}$.

\section{Conclusion}

At present, rolling stock of the new type is being introduced both in Russian Railways JSC and abroad. In this connection, the problem of reliable estimation of the effect of loads on the railway track is highly relevant. Development of measuring equipment for certification of vehicles with application of theoretical approach can significantly improve the quality of measurements. Monitoring systems must work within a wide amplitude range with permissible errors when recording different types of load. The results of the work can be used for metrological support of such systems.

One of the most important factors for accuracy of measurements remains the choice of the strain recording method, which will be least affected by the influencing factors. For this purpose, the analysis of effect of various factors in calculation of loads by the two most common methods was performed using the numerical model. The stress-strain state of the rail under the load of two types and redistribution of deformations with a change in rigidity of the under-rail base was estimated. The effect of displacement of strain registration points on the calculation results was discussed, which was the case with asymmetric installation of the primary transducers along the rail web height. These results can be used to select the data registration method, improvement and detailed study of new methods, as well as metrological support of dynamic forces monitoring systems in the "wheel-rail" system.

\section{References}

1. S.A. Bekher, A.O. Kolomeets, L.N. Stepanova, A.S. Kochetkov, Kontrol'. Diagnostika [Testing. Diagnostics], 7, 68-72 (2016). (in Russian)

2. V.A. Gapanovich, Zheleznodorozhnyj transport [Railway Transport], 10, 10-15 (2016). (in Russian)

3. P.A. Ivanov, Zheleznodorozhnyj transport [Railway Transport], 10, 16-18 (2016). (in Russian) 
4. D.N. Losev, Transport Innovation, 4 (22), 9-10 (2015). (in Russian)

5. I.I. Galiev, V.A. Nekhaev, V.A. Nikolaev, Izvestia Transsiba [Journal of Transsib Railway Studies], 1, 107-112 (2012). (in Russian)

6. GOST P 55050-2012. Railway rolling stock. Permissible exposure norms to the railway track and test methods (Standartinform, Moscow, 2013). (in Russian)

7. V.S. Kossov, A.A. Lunin, D.A. Knjazev, M.V. Timakov, Vestnik transporta Povolzhya, 4 (58), 63-68 (2016). (in Russian)

8. S.A. Bekher, L.N. Stepanova, A.O. Kolomeets, A.A. Popkov, RU Patent 2625256 (2016). (in Russian)

9. D.R. Ahlbeck, H.D. Harrison, The Shock and Vibration Digest, 12 (10), 31-41, (1980).

10. L. Bocciolini, A. Bracciali, L. Di Benedetto, R. Mastandrea, F. Piccioli, Proceedings of the Second International Conference on Railway Technology: Research, Development and Maintenance, ed. by J. Pombo (Civil-Comp Press, Stirlingshire, Scotland, 2014).

11. A.V. Favorskaya, N.I. Khokhlov, V.A. Miryakha, Bjulleten' Obyedinennogo uchenogo soveta OAO RZhD [Bulletin of the Joint Scientific Council of JSC Russian Railways], Vol. 1, 49-63 (2018). (in Russian)

12. M. Bogdevicius, R. Zygiene, G. Bureika, S. Dailydka, Vehicle System Dynamics 54 (5), 689-705 (2016).

13. A.A. Shabana, J.R. Sany, Nonlinear Dynamics, Vol. 26, Issue 2, 179-212 (2001).

14. DIN EN 14363-2016. Railway applications - Testing for the acceptance of running characteristics of railway vehicles - Running Behaviour and stationary tests; German version 04.30.2016.

15. S.A. Bekher, T.V. Sych, A.O. Kolomeets, A.S. Kochetkov, The Siberian Transport University Bulletin (to be published). 